\title{
Using statistical methods to determine the load-bearing capacity of rectangular CFST columns
}

\author{
Glib Vatulia ${ }^{1 *}$, Yevhen Orel $^{1}$, Maryna Rezunenko ${ }^{2}$, and Nataliia Panchenko ${ }^{2}$ \\ ${ }^{1}$ Ukrainian State University of Railway Transport, Structural Mechanics and Hydraulics Department, 7 Feuerbach Sq., \\ 61050 Kharkiv, Ukraine \\ ${ }^{2}$ Ukrainian State University of Railway Transport, Applied Mathematics Department, 7 Feuerbach Sq., 61050 Kharkiv, Ukraine
}

\begin{abstract}
In the current practice of construction and design of transport facilities, structures with external reinforcement are commonly used which effectively resist compression. The use of steel-concrete and composite structures enables us to reduce material consumption and cost of structures significantly. There are a few established approaches used to evaluate the load-bearing capacity of steel-concrete structures under axial and eccentric compression, each being based on the initial prerequisites, which underlie the calculation formulas. In this paper, the functional relationship of the value of the maximum load-bearing capacity of rectangular concrete-filled steel tubular (CFST) columns under axial compression with the random eccentricity is plotted. A regression model is proposed based on the methods of mathematical statistics, which allows for the evaluation of the impact of geometrical and physical characteristics of rectangular CFST columns on the value of their load-bearing capacity. The correspondence of the obtained model to the experimental data, as well as the significance of the regression parameters are confirmed by Fisher and Student criteria.
\end{abstract}

\section{Introduction}

Due to the rapid development of scientific and technological progress, almost any structural solutions of buildings and structures can be implemented. The introduction into the practice of construction of composite structures, the elements of which are made of reinforced concrete and/or composite reinforced concrete, reduction in material, power consumption and the duration of construction works can be achieved [1-4].

Over the past four decades, researchers from the United States, Japan, China, Russia, Ukraine and other countries have conducted multiple experimental studies on the exhaustion of load-bearing capacity and the assessment of stress-strain state of steel-concrete (tubular concrete) columns.

The priority issue of structure designing is ensuring the strength and reliability of the structures, which should be solved, first of all, on the basis of calculation methods that satisfy all the requirements, according to numerous studies in this field [5-13]. The authors propose to use regression analysis as one of these methods - a statistical research method that allows for evaluation of the degree of the impact of independent factors on the dependent variable.

\section{Purpose and methods of the study}

The purpose of this study is to plot a functional dependence of the maximum load-bearing capacity of rectangular CFST columns under axial compression with random eccentricity on various physical and geometric characteristics.

Experimental data obtained by researchers from different countries over the past decades were used as a material for the statistical analysis of the load-bearing capacity of columns.

Such a methodology has already been used by the authors to find the maximum load-bearing capacity of various circular CFST columns [14], as well as long square columns [15].

The method of correlation regression analysis with the parameters listed below was used to solve the problem:

- tube thickness $t \geq 2,0 \mathrm{~mm}$;

- ratio of cross-sectional dimensions $0,5 \leq b / h \leq 1$ at $90 \leq b \leq 325 \mathrm{~mm}$;

- ratio $L / b \leq 4$, at $300 \leq L \leq 1220 \mathrm{~mm}$;

- yield strength of steel $200 \leq \sigma_{y} \leq 490 \mathrm{MPa}$;

- modulus of elasticity of steel and concrete $1,68 \times 10^{5} \mathrm{MPa} \leq E_{s} \leq 2,17 \times 10^{5} \mathrm{MPa}$ and $2,0 \times 10^{4} \leq E_{c}$ $\leq 4,4 \times 10^{4} \mathrm{MPa}$, respectively;

- prism strength of concrete $16 \leq f_{c, p r i z m} \leq 110 \mathrm{MPa}$.

A correlation analysis of the effect of each parameter on the value of the bearing capacity has been conducted. However, it was shown that the combined influence of several factors should be taken into account for plotting an adequate mathematical model. Thus, the following regression equation (1) could be obtained:

$$
\bar{N}=a_{0}+\sum_{i=1}^{k} a_{i} x_{i},
$$

* Corresponding author: glebvatulya@gmail.com 
where $\bar{N}$ is approximate maximum value of CFST columns load-bearing capacity,

$x_{1}=b h f_{c, p r i z m}, x_{2}=L \sigma_{y}, x_{3}=t^{3} \sigma_{y} E_{s}, x_{4}=\frac{(b-t) t^{2}}{E_{c}}$

The adequacy of the obtained model is proven by the coefficient of determination $R^{2}$ being 0,998 , as well as the mean approximation error:

$$
\Delta=\frac{1}{n} \sum_{i=1}^{n} \frac{\left|N_{\exp }-N_{\text {theor }}\right|}{N_{\exp }} 100 \% \approx 5,92 \%,
$$

where $N_{\text {theor }}$ is value of CFST columns load-bearing capacity calculated using formula (1); $N_{\text {exp }}$ - experimental value of load-bearing capacity.

Microsoft Office Excel software was used for the calculations.

Fig. 1 presents the experimental and calculated data of the values of the load-bearing capacity of columns.

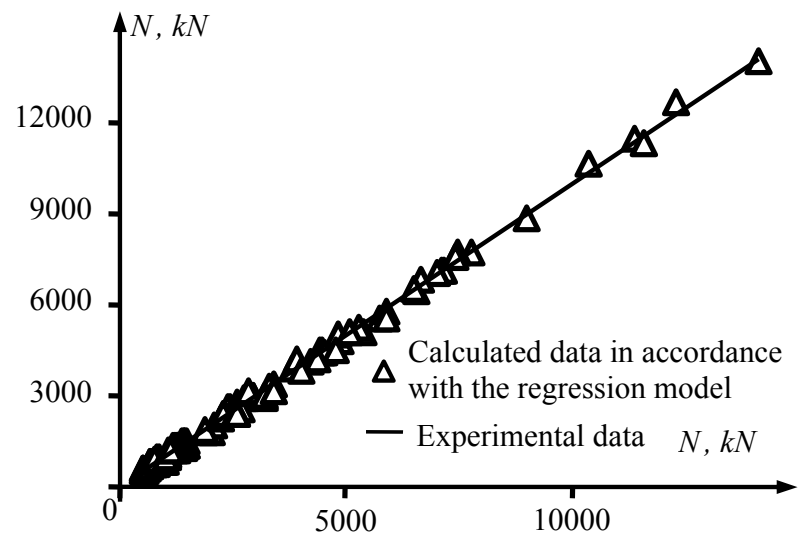

Fig. 1. Load-bearing capacity of columns.

\section{Analysis of the results}

The equation for multifactor regression was obtained on the basis of 134 observations of rectangular CFST columns [7, 10, 13]:

$$
\begin{gathered}
\bar{N}=-68,332+7,19 \times 10^{-4} x_{1}+4,76 \times 10^{-3} x_{2}+ \\
+1,34 \times 10^{-5} x_{3}+4,31 x_{4} .
\end{gathered}
$$

To answer the question, how much the obtained regression coefficients may differ from the exact values, confidence intervals for each coefficient were found with a probability $P=0,95$ :

$$
\begin{aligned}
-107,687 & \leq a_{0} \leq-28,978 ; \\
7,01 \times 10^{-4} & \leq a_{1} \leq 7,38 \times 10^{-4} ; \\
4,473 \times 10^{-3} & \leq a_{2} \leq 5,042 \times 10^{-3} ; \\
1,13 \times 10^{-5} & \leq a_{3} \leq 1,54 \times 10^{-5} ; \\
3,875 & \leq a_{4} \leq 4,745 .
\end{aligned}
$$

The authors have analyzed the obtained equation using the Fisher and Student criteria, which confirm the correspondence of the obtained model to the experimental data and the significance of the regression parameters.
In Table 1, the correlation coefficients of the factors were presented.

Table 1. Correlation matrix.

\begin{tabular}{|c|c|c|c|c|c|}
\hline & $\bar{N}$ & $x_{1}$ & $x_{2}$ & $x_{3}$ & $x_{4}$ \\
\hline $\bar{N}$ & 1,000 & 0,926 & 0,765 & 0,595 & 0,538 \\
\hline$x_{1}$ & 0,927 & 1,000 & 0,522 & 0,433 & 0,501 \\
\hline$x_{2}$ & 0,765 & 0,522 & 1,000 & 0,638 & 0,408 \\
\hline$x_{3}$ & 0,595 & 0,433 & 0,638 & 1,000 & 0,634 \\
\hline$x_{4}$ & 0,538 & 0,501 & 0,408 & 0,634 & 1,000 \\
\hline
\end{tabular}

Analysis of residuals $\left(N_{\text {exp }}-N_{\text {theor }}\right)$ using Pearson's criterion shows that they are normally distributed with the zero mathematical expectation and corrected mean square deviation $S=133,953$.

Fig. 2 shows the bar graph of residuals. All values of the sample lie within $[-3 S ; 3 S]$, while $72 \%$ residuals belong to $[-S ; S], 95 \%$ are within $[-2 S ; 2 S]$.

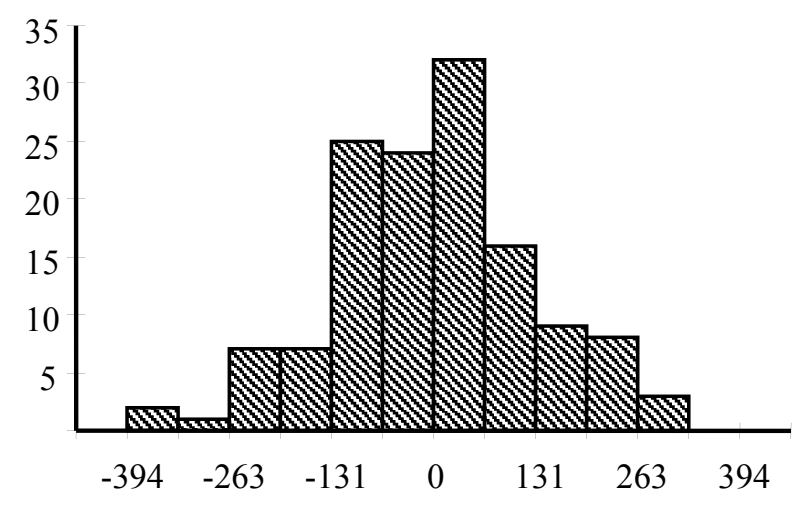

Fig. 2. Bar graph of residuals.

Dependence of the absolute error $\frac{\left|N_{\exp }-N_{\text {theor }}\right|}{N_{\exp }}$ on individual parameters is shown in Fig. 3.

The analysis of the regression model factors shows that the main contribution to the value of the load-bearing capacity of CFST columns is given by the first summand $b h f_{c, \text { prizm }}$ (Fig. 5).

Such dependence is well approximated with the linear function $y=0,0012 x+818,65$ and gives the coefficient of determination $R^{2}=0,8619$.

Thus, it can be stated that $86 \%$ of the change of the load-bearing capacity is due to the combined impact of the cross-sectional area and the value of the prism strength of the concrete, but this is insufficient to obtain a more accurate profile of the behaviour of columns, which leads to the need to take into account other characteristics (length, yield strength of steel, modulus of elasticity of steel and concrete) and their combined influence.

The plotted model enables us to estimate the degree of effect of the parameters of rectangular CFST columns on the value of the bearing capacity. Fig. 4 below shows the dependence of the increase in the load-bearing capacity (\%) on an increase in the tube thickness by $10 \%$ for various characteristics of columns.

Fig. 4 illustrates that an increase in the tube thickness of $10 \%$ in some cases can cause an increase in the loadbearing capacity of the column of up to $17 \%$. 


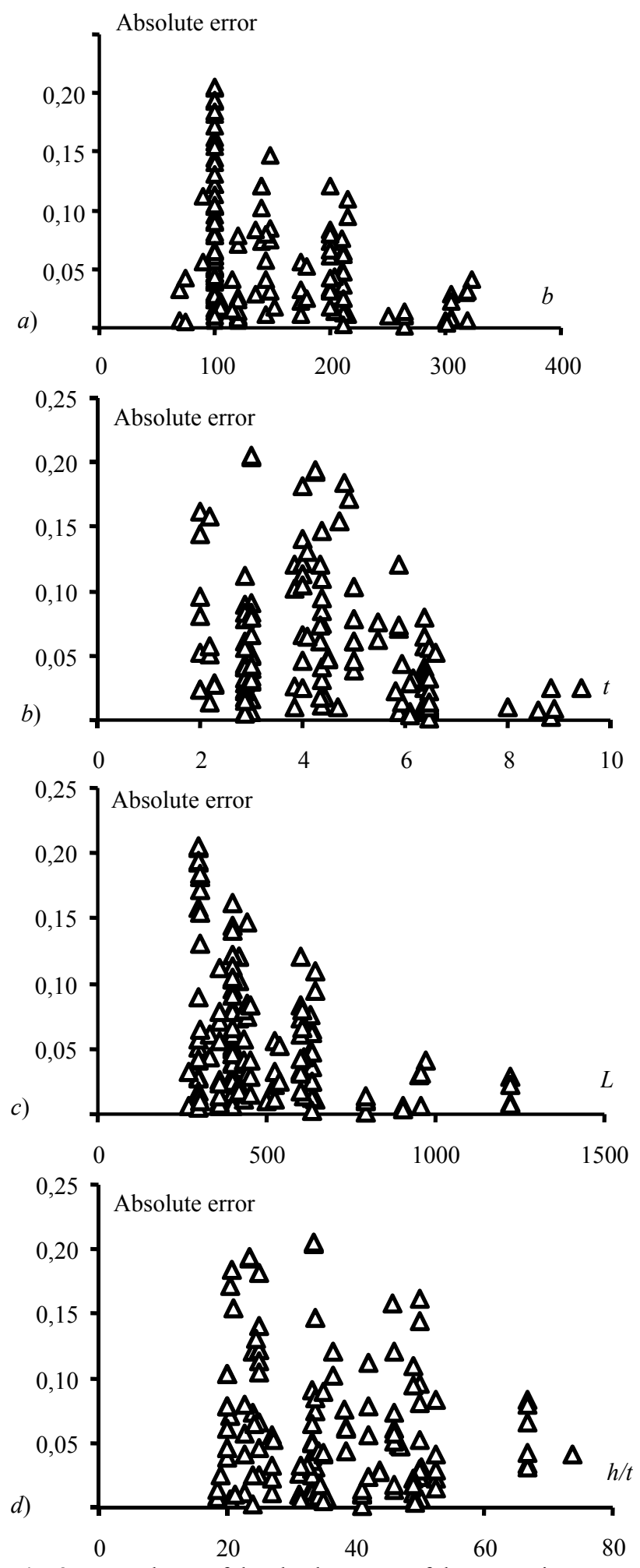

Fig. 3. Dependence of the absolute error of the regression model: $a$ ) on $b ; b$ ) on tube thickness $t ; c$ ) on column length $L$, d) on $h / t$ value.

The adequacy of the proposed model is confirmed by the authors' comparative analysis of the error in the calculated value of the load-bearing capacity of columns calculated using the proposed method and the one obtained using Eurocode 4 calculation procedure.
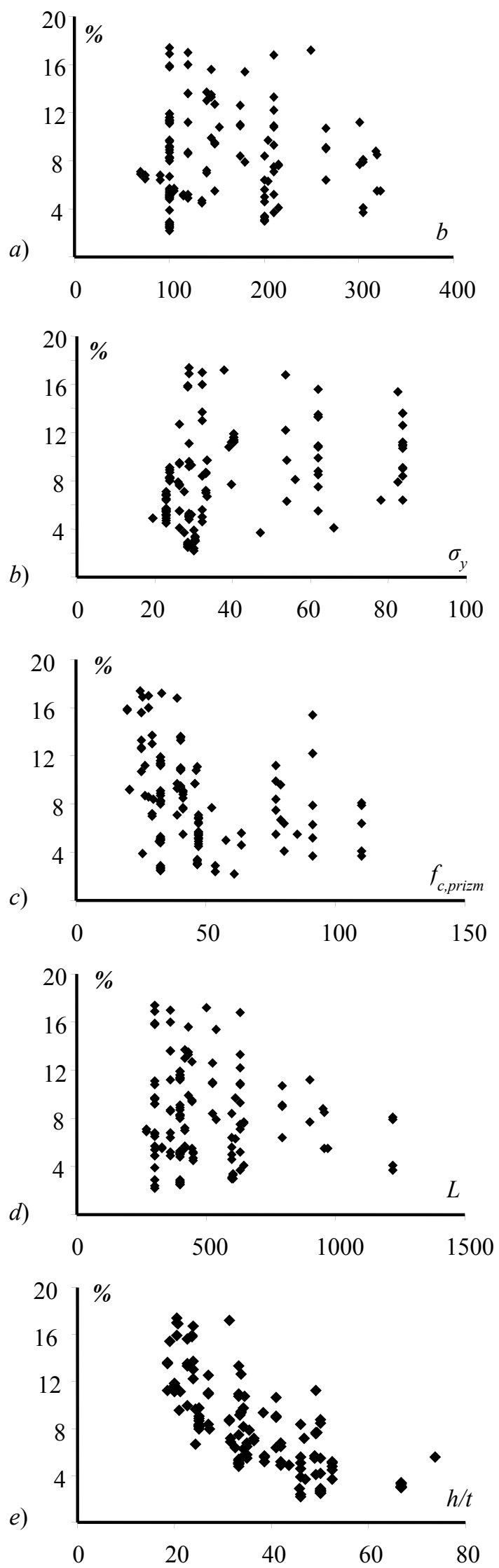

Fig. 4. Change of the value of the load-bearing capacity (\%) when the tube thickness is increased by $10 \%$. 


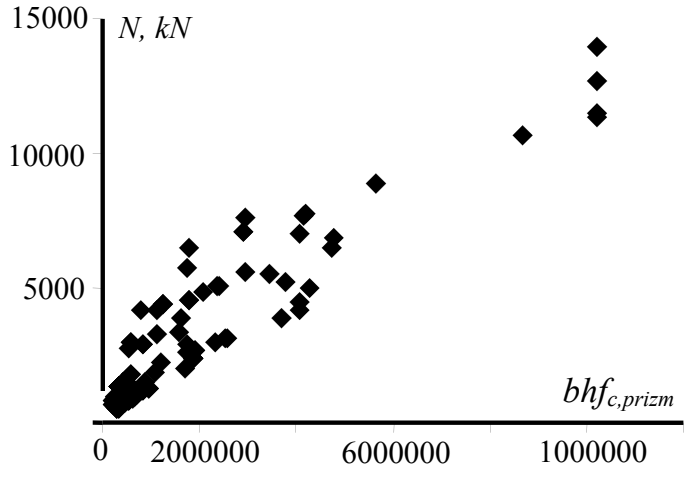

Fig. 5. Dependence between the maximum load-bearing capacity and $b h f_{c, p r i z m}$.

In Fig. 6, the triangles correspond to the error obtained using the statistical analysis methods, while the squares to those of Eurocode 4.

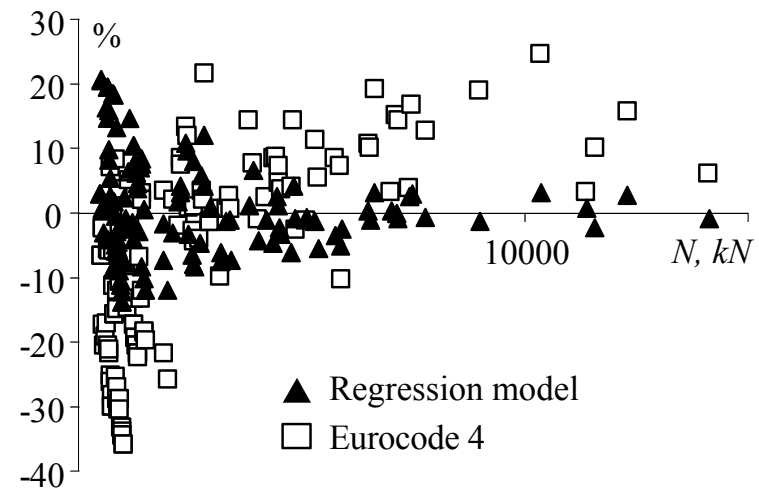

Fig. 6. Error of computation (\%).

\section{Conclusions}

As a result of the study, a functional dependence of the maximum value of the load-bearing capacity of rectangular CFST columns under axial compression has been obtained. The obtained dependence has been analysed using the methods of mathematical statistics.

The comparative analysis of the theoretical and experimental results confirms a sufficient reliability of the obtained model within $6 \%$.

The authors performed a comparative analysis of the calculated value of rectangular CFST columns loadbearing capacity with the value calculated using the methods of Eurocode 4.

The proposed model helps us to predict the value of the load-bearing capacity using different initial parameters together with columns optimization.

\section{References}

1. E. Chikhladze, G. Vatulia, Y. Kitov, P. Basis for calculation and design of composite and steel-concrete constructions, Transport of Ukraine, 104 (2006)

2. T. Yamamoto. Experimental study of the size effect on the behaviour on concrete filled circular steel tube columns under axial compression, J. Struct. Constr. Eng., Transactions of AIJ, 561, 237-244 (2002)

3. M. Mursi, B. Uy, M. Bradford, Interaction buckling of concrete filled columns using high-strength steel, ASSCCA'03 International Conference Advances in Structures (ASCCS-7), Sydney, Australia, 863-869 (2003)

4. L. Han, T. Zhong, L. Wei, Effects of sustained load on concrete-filled hollow structural steel columns, Journal of Structural Engineering ASCE 9, 1392-1404 (2004)

5. A. Krishan, A. Melnitchuk, Strength and deformability of short tube confined concrete columns of square cross section, News of KSUAE, 3(29), 6-50 (2014)

6. L. Storozhenko, D. Ermolenko, O. Lapenko, Tube confined concrete, ASMI, LLC, 306 (2010)

7. I. Nishiyama, S. Morino, K. Sakino, H. Nakahara, Summary of Research on Concrete-Filled Structural Steel Tube Column System Carried Out Under The US$J A P A N$. Cooperative Research Program on Composite and Hybrid Structures, 176, (2002)

8. Design of composite steel and concrete structures Part 1-1: General Rules and Rules for Bridges, EN 1994-1: 2001. Eurocode 4, Brussels, 96 (2006)

9. M. Xinbo, S. Zhang, C. Goode, Comparison of design methods for circular concrete filled steel tube columns in different codes, 8th International Conference on Steel-Concrete Composite and Hybrid Structures, Harbin, Harbin University of Science and Technology, 30-37 (2006)

10. A. Kuranovas, D. Goode, A. Kvedaras, S. Zhong, Load-bearing capacity of concrete-filled steel columns, Journal of Civil Engineering and Management, 15(1), 21-33 (2009)

11. Y. Hao, Y. Lan, Research on the axial bearing capacity of concrete-filled rectangular steel tube short column, Applied Mechanics and Materials, 368, 1710-1717 (2013)

12. O. Seraya, D. Demin, Linear regression analysis of a small sample of fuzzy input data, Journal of Automation and Information Sciences, 44(7), 34-48 (2012)

13. G. Vatulia, D. Petrenko, M. Novikova, Experimental estimation of load-carrying capacity of circular, square and rectangular CFTS columns, Scientific Bulletin of National Mining University, 6, 97-102 (2017)

14. G. Vatulia, M. Rezunenko, Ye. Orel, D. Petrenko, Regression equations for circular CFST columns carrying capacity evaluation, DYN-WIND'2017, MATEC Web of Conferences, 107, 00051 (2017)

15. G. Vatulia, M. Rezunenko, D. Petrenko, S. Rezunenko, Evaluation of the carrying capacity of rectangular steel-concrete columns. Civil and Environmental Engineering, 14, 76-83 (2018) 